\title{
Reproductive Ecology of the Gobiid Fish Eviota abax at Nobeoka, Japan, with Notes on Geographic Variation ${ }^{1}$
}

\author{
Masanori Taru ${ }^{2}$ and Tomoki Sunobe ${ }^{3}$
}

\begin{abstract}
The reproductive behavior and spawning cycle of the gobiid fish Eviota abax were observed in a rocky tide pool at Nobeoka, Miyazaki, Japan. Both sexes maintained nonterritorial, overlapping home ranges. The spawnings took place at the low tide of neap to spring tidal periods. Matings varied in each spawning cycle, but males did not simultaneously mate with multiple females. Males were larger than females in the spawning pairs. After spawning, only the male guarded the egg mass. Although separated by $900 \mathrm{~km}$, the basic patterns of reproductive ecology were similar at Nobeoka to those reported earlier for this species from Kominato, Chiba, Japan; nest entrances were smaller at Nobeoka than at Kominato, and larger males kept their home ranges longer at Nobeoka.
\end{abstract}

INTRASPECIFIC GEOGRAPHICAL variation in behavior has been the focus of recent research on the mechanism of evolution of behavior brought about by environmental variation (Foster and Endler 1999). Such behavioral variation could result in reproductive isolation of individuals from different habitats. Therefore, it is important to discuss conspecific behavioral variation among populations from different habitats to elucidate possible evolutional sequences of specialization (Verrell 1999).

However, comparative studies on geographic variation of behavior among reef fishes whose larvae disperse by water currents and settle out in different habitats following metamorphosis are rare. Yanagisawa (1982) investigated the reproductive ecology of the gobiid fish Amblyeleotris japonica from two different populations; Akagawa and Okiyama (1997) examined the reproductive and feeding behavior of the file fish Rudarius ercodes from four populations.

${ }^{1}$ Manuscript accepted 14 May 2001.

${ }^{2}$ Marine Biology Laboratory, Faculty of Science, Toho University, 2-2-1, Miyama, Funabashi-shi, 2748510, Japan (E-mail: taru@bio.sci.toho-u.ac.jp).

${ }^{3}$ Natural History Museum and Institute, Chiba, 9552 Aoba-cho, Chuo-ku, Chiba-shi, 260-8682, Japan.

Pacific Science (2002), vol. 56, no. 1:35-40 (C) 2002 by University of Hawai'i Press. All rights reserved
In this paper we describe the spawning cycle, mating system, and egg-guarding behavior of the gobiid fish Eviota abax at Nobeoka, Miyazaki, Japan, and compare it with the reproductive ecology of another population $900 \mathrm{~km}$ distant at Kominato, Chiba, Japan, previously studied by Taru and Sunobe (2000).

Eviota abax is a small species ( $<50 \mathrm{~mm}$ total length), inhabiting shallow subtidal and lower intertidal rocky shores and coral reefs in southern Japan (Lachner and Karnella 1980). The spawning season is from May to August in Kyushu (Dotsu et al. 1965). Larvae have been collected from June to October, but are particularly abundant from July to August at Kominato (Okabe 1998). Sunobe (1998) described courtship behavior of $E$. abax in an aquarium. The female lays an egg mass on the wall of the nest, and the male guards the embryos for approximately 5 days at $22-28^{\circ} \mathrm{C}$ until hatching (Dotsu et al. 1965, Sunobe and Nakazono 1987).

\section{MATERIALS AND METHODS}

This study was carried out on the rocky shore in front of the Fisheries Research Laboratory of Miyazaki University, located on the east coast of Kyushu Island $\left(32^{\circ} 31^{\prime} \mathrm{N}, 131^{\circ} 42^{\prime}\right.$ E). We observed the behavior of Eviota abax by snorkeling one to three times a day between 0530 and 1900 hours from 7 June to 31 August 1997, except for stormy days. Ob- 
servations were made on 67 days for a total of approximately $169 \mathrm{hr}$. The water temperature varied from 21.3 to $28.7^{\circ} \mathrm{C}$ during the observation period.

A quadrat (1.8 by $5.8 \mathrm{~m}$ ) divided into 213 20 by $20 \mathrm{~cm}$ grid squares was set on a rock face and cobble field at $0-1.5 \mathrm{~m}$ depth inside a tide pool. Before the beginning of observations, from 23 May to 6 June, we captured all individuals of $E$. abax in the observation area with a hand net. They were individually discriminated by the color pattern on the nape and by clipping of the upper or lower part of the caudal fin. Standard length (SL) and total length (TL) were measured and sex was determined by the degree of elongation of the first two dorsal spines (which are elongated by $150-200 \%$ in males) and the shape of the urogenital papilla (Lachner and Karnella 1980). Previously unencountered individuals appearing after the start of observations on 7 June were cataloged in the same manner. The total number of identified males and females was 34 and 50, respectively.

We recorded the swimming tracks for each individual for $5 \mathrm{~min}$ on each sample day. Tracks of male courtship and female response were excluded from data used to determine their home ranges. Subsequently, we estimated the size and boundaries of individual home ranges by combining swimming track data for each individual fish. We noted the degree of abdominal swelling in the females each sample day and assumed that the female had spawned on the same day if the swollen abdomen became substantially reduced. We then analyzed the possible relationships among frequency of spawning, the lunar phase, and the tidal condition, using a tide table for Hososhima, Miyazaki, Japan (Japan Meteorological Agency 1996). When reproductive behavior was observed, the time and code number of the participants were recorded. When the male guarded the egg mass, we also recorded any animal species that the male attacked. After hatching, we measured directly the shortest dimension of the nest entrance that limited access and estimated the depth of nest holes by inserting an aluminum wire and subsequently measuring it.

\section{RESULTS}

Thirty-four males (mean, $27.8 \mathrm{~mm} \mathrm{SL} \pm 4.52$ SD; range, 19.1-37.6 $\mathrm{mm}$ ) and 50 females (mean, $27.1 \mathrm{~mm} \mathrm{SL} \pm 3.14 \mathrm{SD}$; range, 20.9$35.5 \mathrm{~mm}$ ) were seen during the observation period. The mean operational sex ratio (OSR) was male : female $=1: 0.98$ and fluctuated between $1: 0.2$ and $1: 3$. The mean period of time that fish remained at the observation area was 42.0 days (range, $1-88$ days \pm 28.3 SD) for males and 45.8 days (1-89 days \pm 26.3 SD) for females.

Figure 1 shows the arrangement of the finalized home range boundaries between 28 July and 3 August, when observed reproductive behavior was most frequent. Neither sex exhibited any territorial behavior; instead, home ranges of all individuals exhibited considerable overlap with each other. Feeding occurred within the home ranges. Among males, larger individuals retained their home ranges longer than smaller males (Kendall's rank correlation test, $z=2.18, P=0.0293<$ 0.05 , Figure 2). Five instances of male-male aggressive interactions associated with obtaining spawning nests were observed during the study period. Aggressive behavior occurred in the following sequence: males facing each other at 1 to $5 \mathrm{~cm}$, head up with open mouth, lateral display while circling each other with expanded dorsal and caudal fins, darting at adversary male and biting its body. In all five cases, the larger male drove the smaller male away from its periphery, thus winning the aggressive interaction. The males used small holes, rock cracks, or empty shells of the oyster Crassotrea gigas as a spawning nest. The shortest dimension of measured nest hole entrances ranged from 7 to $20 \mathrm{~mm}$ (mean, $11.5 \mathrm{~mm} \pm 4 \mathrm{SD} ; n=12$ ), with nest hole depth ranging from 35 to 140 $\mathrm{mm}$ (mean, $64.5 \mathrm{~mm} \pm 30 \mathrm{SD}$ ).

The number of spawning events observed varied as cyclic ups and downs, when tidal fluctuation was smaller and larger, respectively. Five spawning cycles were recognized during the observation period (Figure 3).

Reproductive behavior was initiated by a male visiting a female's home range. The male approached the female and exhibited 


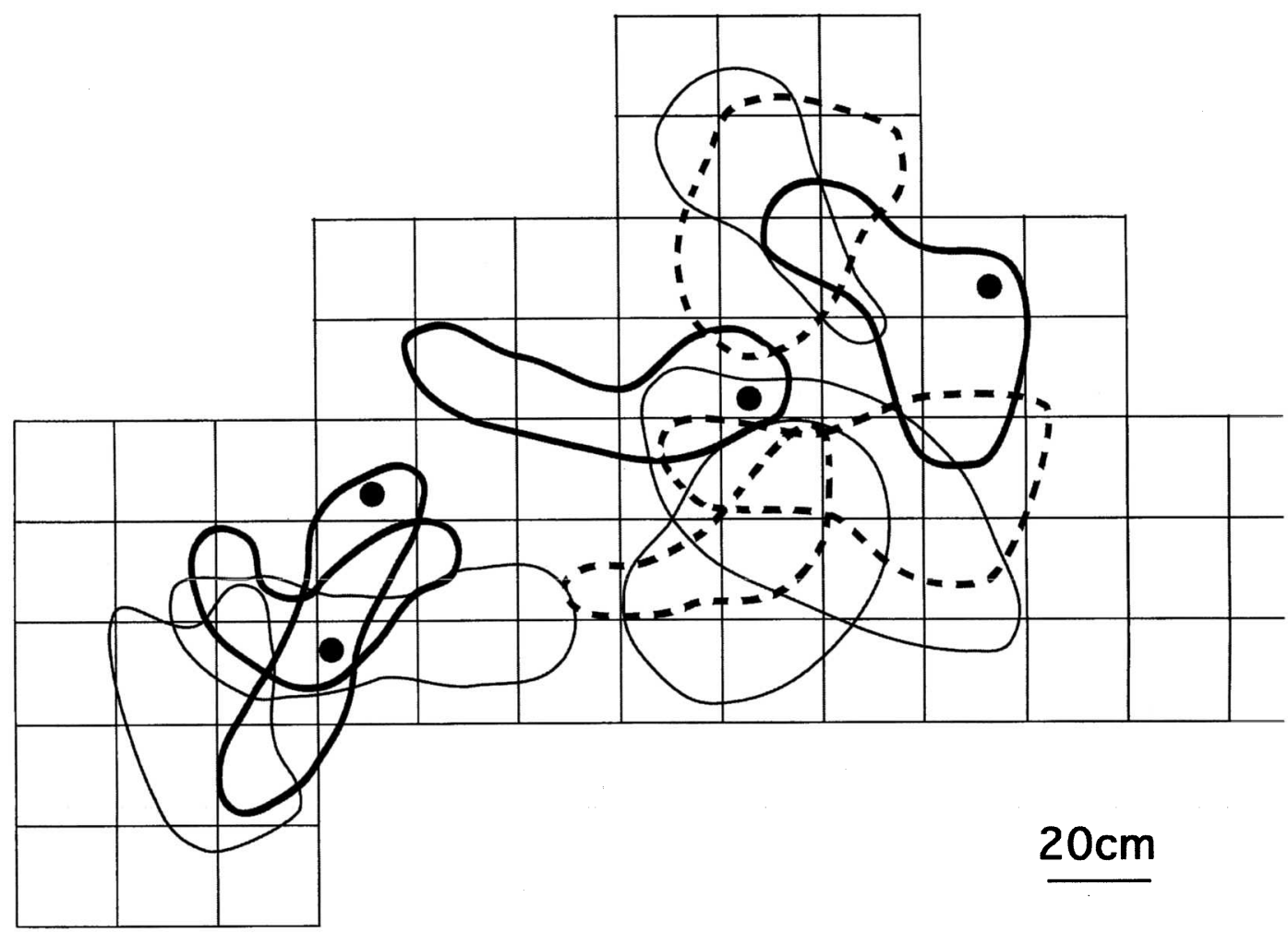

FIGURE 1. Home ranges of all individuals appearing at the study site between 28 July and 3 August. Thick solid, thick broken, and thin solid lines indicate the finalized home range boundaries of egg-guarding males, non-egg-guarding males, and females, respectively. Solid circles show the locations of the males' nests.

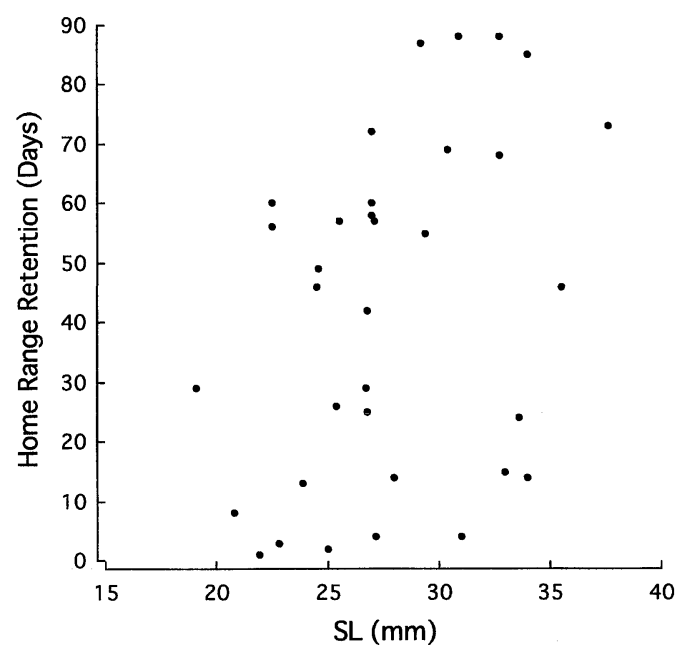

FIGURE 2. Relationship between male body size (standard length [SL]) and retention of home range by males. courtship displays as described by Sunobe (1998). The female responded to the male's displays by following the male to his nest. After the male entered the nest, the female stopped at the entrance. As the male courted from the entrance, the female entered the nest.

Eleven males participated in 18 spawning events: five males mated only once; five other males mated twice; and one male mated three times with different females in successive spawning events. Females spawned once in any given spawning cycle and spawned one to four times during the total observation period. As a group, males were significantly larger than females in the mating pairs (Wilcoxon's signed rank test, $T=15, Z=$ $-3.070, P=0.0021, n=18$, Figure 4). 


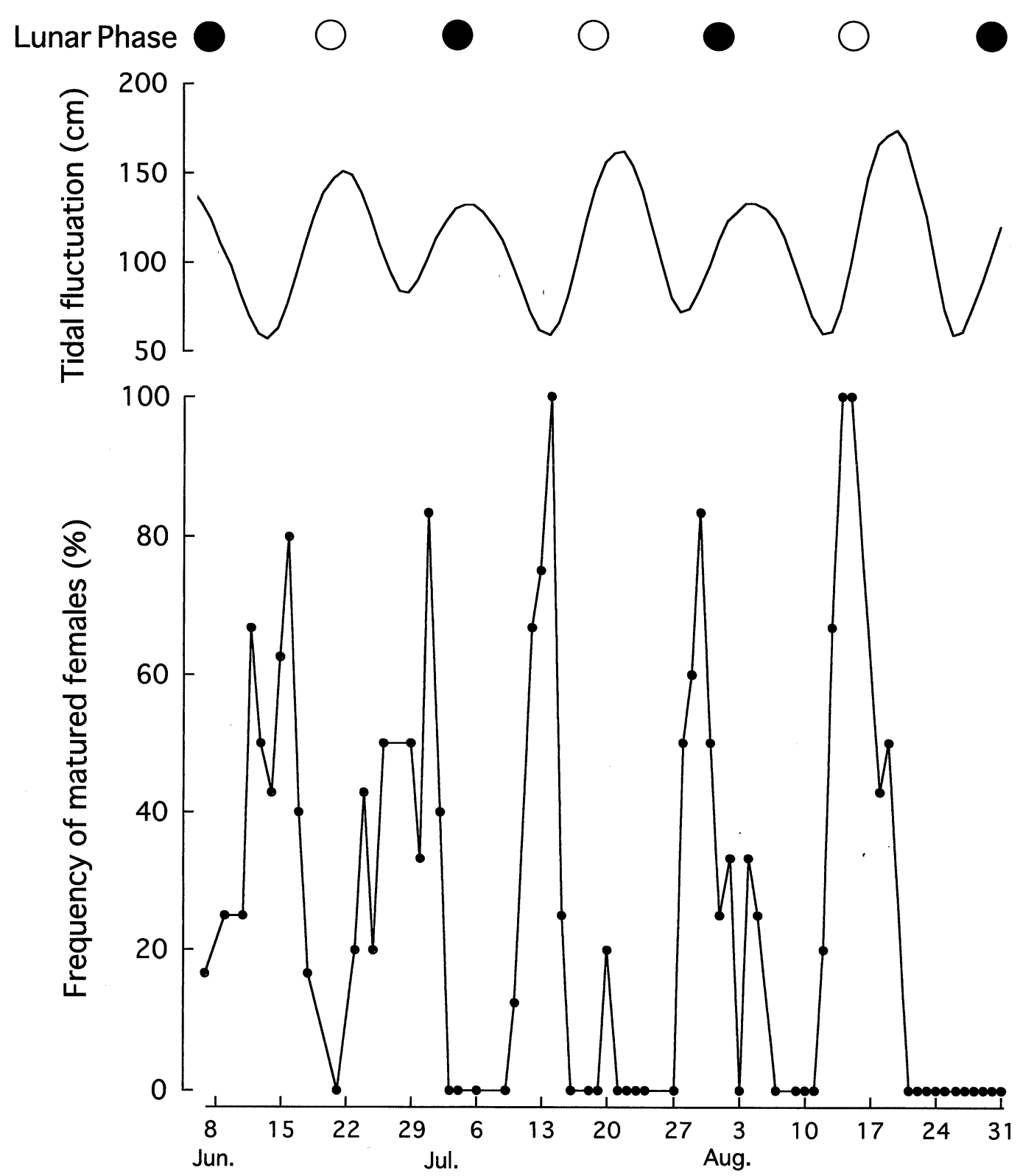

FIGURE 3. Relationship between lunar phase, tidal fluctuation, and number of mature females (classified by abdominal condition) from 7 June to 31 August. Tidal fluctuation was calculated as follows: [(tidal level of the first full tide - tidal level of the first low tide) + (tidal level of the second full tide - tidal level of the second low tide)]/2.

These spawnings were observed from 0620 to 1300 hours, within $3 \mathrm{hr}$ before or after the time of low tide. After spawning, females left the male's nest within $26-80 \mathrm{~min}(55 \pm 16$ $\mathrm{SD}, n=18$ ) of nest entry and returned to their home ranges. The male guarded the egg mass until hatching, which occurred 5 days after spawning. During the egg-guarding period, the male often stayed at the entrance of the nest and attacked approaching animals. 


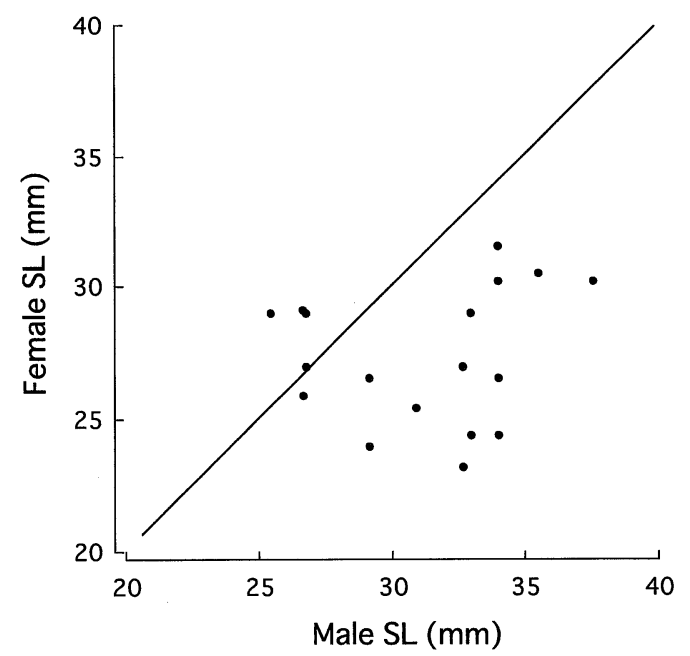

Figure 4. Relationship between male and female body sizes (standard length [SL]) of spawning pairs. A solid line indicates $Y=X$.

These animals included both sexes of E. abax, five other fish species (Bathygobius fuscus, Eviota prasina, Stethojulis interrupta terina, Thalassoma cupido, and Tridentiger trigonocephalus), one species of crab (Heteropilumnus ciliatus), and two shrimp species (Palaemon pacificus and $P$. serrifer).

\section{DISCUSSION}

Studies of the gobiid fish Amblyeleotris japonica (Yanagisawa 1982) and the file fish Rudarius ercodes (Akagawa and Okiyama 1997) have failed to reveal site-dependent differences in the basic pattern of reproductive ecology of these species. Differences were found in utilization of resources such as spawning substrates or spawning nests. Likewise, our study of Eviota abax at Nobeoka revealed the same basic pattern of reproductive ecology for this species as was reported by Taru and Sunobe (2000) for the Kominato population; social systems, mating behavior, and spawning cycles were comparable. However, two differences in utilization of habitat resources were found: size of nest entrance hole and duration of home range maintenance.

The shortest diameter of nest hole entrances observed at Nobeoka (mean, 11.5 $\mathrm{mm} \pm 4 \mathrm{SD}, n=12$ ) was smaller than that reported for the Kominato population (mean, $20 \mathrm{~mm} \pm 7 \mathrm{SD}, n=9$ ) (Mann-Whitney $U$ test, $U=14.0, \quad z=-2.843, \quad P=0.0043)$. Two factors that we observed may account for the difference in nest hole entrance size at these two sites. The standard length of $E$. abax males at Nobeoka ( $27.8 \mathrm{~mm} \pm 4.52 \mathrm{SD})$ is significantly smaller than that of males at Kominato $(32.7 \mathrm{~mm} \pm 4.40 \mathrm{SD}$ [Taru and Sunobe 2000]) (Mann-Whitney $U$ test, $U=$ 144.0, $z=-3.717, P=0.0002 ; n$ [Nobeoka] $=31, n[$ Kominato] $=23)$. In addition, there were four other fish species (Batbygobius fuscus, Eviota prasina, Istiblennius edentulus, and Omobranchus punctatus) that routinely occupied rock holes and cracks as spawning sites at Nobeoka. All of these except $E$. prasina are larger than $E$. abax and may competitively displace $E$. abax from the larger spawning sites. At Kominato, no other species used potential nest sites for $E$. abax and a wider range of larger nest sizes was thus available for the species (unpubl. data).

Larger males maintained their home ranges longer than smaller males at Nobeoka, but no such tendency was found among males in the Kominato population (Taru and Sunobe 2000). There was also a difference in the OSR between these sites: $1: 1.4$ at Kominato (Taru and Sunobe 2000) and 1:0.98 at Nobeoka (Mann-Whitney $U$ test, $U=156.0$, $z=-1.67, P=0.094)$. At Nobeoka, the larger males drove away smaller males as a result of aggressive interaction for nest sites; such interactions were not observed at Kominato (unpubl. data). These results suggest that there may be more male-male competition for females and nests at Nobeoka than at Kominato.

\section{ACKNOWLEDGMENTS}

We are grateful to Takeshi Kanda, Tamotsu Michishita, and the other members of the Fisheries Research Laboratory of Miyazaki University for providing us access to the field site. We also thank Toshio Furota and the other members of the Marine Biology Laboratory of Toho University for their useful advice. 


\section{Literature Cited}

Akagawa, I., and M. Okiyama. 1997. Reproductive and feeding ecology of Rudarius ercodes in different environments. Ichthyol. Res. 44:82-88.

Dotsu, Y., I. Arima, and S. Mito. 1965. The biology of the eleotrid fishes, Eviota abax and Eviota zonura. Bull. Fac. Fish. Nagasaki Univ. 18:41-49 (in Japanese with English abstract).

Foster, S., and J. Endler. 1999. Introduction and aims. Pages xi-xxii in S. Foster and J. Endler, eds. Geographic variation in behavior. Oxford University Press, New York.

Japan Meteorological Agency. 1996. Tide tables for the year 1997 (in Japanese).

Lachner, E., and S. Karnella. 1980. Fishes of the Indo-Pacific genus Eviota with descriptions of eight new species. Smithson. Contrib. Zool. 315:1-125.

Okabe, K. 1998. Rocky shore larval and juvenile fishes collected by light-trap sam- pling at Kominato, Boso Peninsula, central Japan. Jpn. J. Ichthyol. 43:79-88 (in Japanese with English abstract).

Sunobe, T. 1998. Reproductive behavior in six species of Eviota (Gobiidae) in aquaria. Ichthyol. Res. 45:409-412.

Sunobe, T., and A. Nakazono. 1987. Embryonic development and larvae of genus Eviota (Pisces: Gobiidae) I. Eviota abax and E. storthynx. J. Fac. Agric. Kyushu Univ. 31:287-295.

Taru, M., and T. Sunobe. 2000. Notes on reproductive ecology of the gobiid fish Eviota abax at Kominato, Japan. Bull. Mar. Sci. 66:507-512.

Verrell, P. 1999. Geographic variation in sexual behavior. Pages 262-286 in S. Foster and J. Endler, eds. Geographic variation in behavior. Oxford University Press, New York.

Yanagisawa, Y. 1982. Social behavior and mating system of the gobiid fish $\mathrm{Am}$ blyeleotris japonica. Jpn. J. Ichthyol. 28:401422. 